\title{
Socio-economic inequality in national incidence and mortality rates of COVID-19 in India: An Ecological Study
}

Alok Ranjan ${ }^{1}$, Prabhat Kumar Singh ${ }^{2}$, Sanjay Pandey ${ }^{3}$, Chandra Mani Singh $^{4}$, Arshad Ayub ${ }^{5}$

${ }^{1}$ Assistant Professor (Biostatistics), Department of Community \& Family Medicine, All India Institute of Medical Sciences, Patna; ${ }^{2}$ Professor (Department of Anesthesia) and Director, All India Institute of Medical Sciences, Patna; ${ }^{3}$ Additional Professor, Department of Community \& Family Medicine, All India Institute of Medical Sciences, Patna; ${ }^{4}$ Professor \& Head, Department of Community \& Family Medicine, All India Institute of Medical Sciences, Patna; ${ }^{5}$ Senior Resident, Department of Community \& Family Medicine, All India Institute of Medical Sciences, Patna

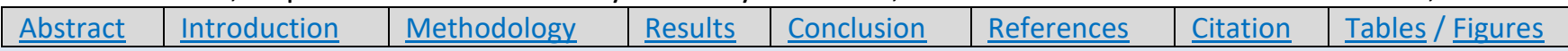

\section{Corresponding Author}

Dr. Sanjay Pandey, Department of Community \& Family Medicine, All India Institute of Medical
Science, Phulwari Sharif, Patna
E Mail ID: drsanjayp69@gmail.com

\section{Citation}

Ranjan A, Singh PK, Pandey S, Singh CM, Ayub A. Socio-economic inequality in national incidence and mortality rates of COVID-19 in India: An Ecological Study. Indian J Comm Health. 2020;32(4):665-676. https://doi.org/10.47203/IJCH.2020.v32i04.010

\section{Source of Funding: Nil Conflict of Interest: None declared}

\section{Article Cycle}

Received: 15/11/2020; Revision: 29/11/2020; Accepted: 15/12/2020; Published: 31/12/2020

This work is licensed under a Creative Commons Attribution 4.0 International License.

\section{Abstract}

Background: There are sufficient evidences on the association of epidemiological and clinical features of the patients with COVID-19 but still there are paucity of evidences on socio-economic aspects of this disease. An ecological study has been carried out with aim to assess the associations of the Human Development Index (HDI) and its components of each states and Union territories in India with incidence and mortality from COVID-19. Methods: Information on confirmed cases and deaths have been extracted from the data on the website of Covid India Organization and the data on $\mathrm{HDI}$ and its components have been extracted from various national and international agencies. Regression analysis was performed which showed a direct significant association ( $p$ values $<0.05$ ) of incidence and mortality rates with $\mathrm{HDI}$ and its components at the national level. Concentration index was estimated to measure socio-economic inequality in COVID-19 incidence and mortality rates with $95 \%$ confidence interval $(\mathrm{Cl})$, which were $0.41(0.27-0.54)$ and $0.42(0.26-0.58)$ for incidence and mortality rates of COVID-19 respectively. Results: The high incidence and mortality rates of COVID-19 in states and union territories of India with high HDI and its components warrant priority for interventions by the national health policy-makers. Cases detection and screening facilities need to be scaled up in states and UTs with low incidence and mortality rates to minimize the under-reporting of the cases.

\section{Keywords}

\section{COVID-19.}

\section{Introduction}

The 2019 novel coronavirus (SARS-cov2) or COVID-19 as it is now called is rapidly spreading worldwide from its place of origin in Wuhan City of Hubei Province of China. The virus was initially named as 2019 novel coronavirus (2019-nCOV) by the WHO, then was later on updated as SARS-CoV-2 and the name of the disease as coronavirus disease 2019 (COVID-19)(1,2). By November 27, 2020, the disease had infected more than 61million cases and 1.43 million people died so far at the global level (3). 
In India, nearly 9.3 million cases and 0.13 million deaths have been reported so far.(4)

Even though a high proportion of the infected persons have manifested with mild symptoms not requiring hospitalization, it has been observed that a significant proportion of the individuals have the illness of moderate to severe nature requiring immediate critical care. Common signs and symptoms of the disease involve fever, shortness of breath, cough, respiratory and breathing problems. The infection can make severe acute respiratory syndrome, kidney failure, pneumonia, and even death in more severe cases.(5) (6) High incidence of mortality among elderly population or those with comorbid conditions were reported.(7)

It has been observed an obvious differences in epidemic spread and fatality rates among regions, but factors related to these regional differences are unclear. It is important to explore the specific reasons for variations in burden of disease. Factors like size and structure of population, geographical areas, population density, and human development index could be related to the extent of disease spread and transmission.

There are sufficient evidences on the association of aetiology with incidence and mortality due to COVID19 but still there are paucity of evidences on many aspects of this disease. Socio-economic factors could be one of the important aspects which have not been addressed so far. Considering these facts into account, an ecological study has been carried out with following aims and objectives.

\section{Aims \& Objectives}

1. To assess the associations of specific elements of the Human Development Index (HDI) like life expectancy at birth, educational status and per capita income of each states and Union territories in India with incidence and mortality from COVID-19.

2. To examine the socio-economic inequality in morbidity and mortality of COVID-19 across the regions in India. Also Besides these, association of other independent variables such as percentage of urban population have also been evaluated.

\section{Material \& Methods}

Study Design: Ecological study

Study Population : All confirmed cases of COVID-19 reported from all the states and Union Territories of India until November 23, 2020.

\section{Strategy for data collection :}

I. Data of COVID-19: For the study, data of confirmed cases and deaths have been extracted from the website of Covid India Organization till 23rd November 2020.(4) Three epidemiological indicators were adopted as dependent variables: i) COVID-19 incidence rate/100 000 inhabitants, ii) COVID-19 mortality rate/100 000 inhabitants, and iii) COVID-19 case fatality rate per 10000 Covid19 infection. Since the number of incidences and deaths from the disease is changing daily and is being updated based on the rates of diagnosis and reports from different regions of India, the data in this article are based on the statistics of the reports by the above agency.

The independent variables used in the study are as follows:

II. Human Development Index (HDI) Data: The Human Development Index (HDI) is a composite index that takes into consideration: health, education and per capita income. This is used as a summary measure of three dimensions of human well-being, viz, a long and healthy life, education, and a decent standard of living, which is usually constructed by combining three indices, viz, life expectancy index, education index and income index. Regions specific HDI data have been accessed from the United Nations Development Programme (UNDP) site. (8) The HDI gives a value between zero and one. The human development index allows regional comparisons. The HDI is a review of measures in human advance. The HDI determines the average success in a nation in three major aspects of human progress, including long and healthy life, access to knowledge, and living standards.(9) (10) (11)

III. State Wise Population Data: State and Union Territories wise projected population data for the year 2019 were retrieved from portal of the Unique Identification Authority of India, Govt. of India . (12)

IV. State-wise life expectancy at birth data (201216) : Sample Registration System, Registrar General and Census Commissioner, Ministry of Home Affairs, Government of India periodically publish data on life expectancy at birth. The data had been retrieved from there. (13)

V. Literacy Rate (\%) Data: State-wise literacy rate data were retrieved from the document 
available in Office of the Registrar General, GOI.(13)

VI. School education up to secondary level and above: State-wise data retrieved from the published document of GOI.(14)

VII. Below Poverty Line (\%): State-wise data retrieved from the data available on Reserve Bank of India website.(15)

VIII. Per Capita Income (in Rs and in US\$): State-wise per capita income data were retrieved from the Ministry of Statistics and Programme Implementation, GOI.(16)

IX. Percent of Urban Population: State-wise proportion of urban population retrieved from the Census of India.(17)

Data Analysis: It is reasonable to assume people in the same region are independent and identical with the same probability of being infected and diagnosed as a confirmed case. Under this assumption, we estimated incidence rate and mortality rate due to Covid19 per 100,000 population for each region using population at risk. Case-fatality rate is defined as the proportion of death among the confirmed cases.

However, not all infected people are diagnosed and counted into the confirmed cases. We assume people in the same region has the same probability to get infected and die due to COVID-19 while the risk of death is different among different regions. Hence, we estimated the case-fatality rate per 10,000 COVID-19 cases of each region taking cumulative confirmed cases as on the date of data retrieval.

All the statistical analysis was done using STATA version 10 (Stata Corp, USA). Normality condition of all the dependent and independent variables were tested using Shapiro-Wilk W test of normality. It was found that some of the variables were not normally distributed $(p<0.05)$ when measured on the usual scale. Dependent variables like incidence rate ( $p$ value $=0.386)$, mortality rate ( $p$-value $=0.163)$, and case-fatality rate $(p$-value $=0.104)$ were found to be normality distributed when these variables were transformed to log scale. Independent variables such as Per capita income (Rs), Per Capita Income (US\$), density of urban population were also transformed to log scale. These log transformed variables were found to be normally distributed on log scale ( $p$ value $>0.05)$. Normality assumption is one of the important assumptions for applying regression analysis. Student's t-test was applied to test the regression and correlation coefficients.

Concentration index was used to measure the socioeconomic inequality, where the cumulative percentage of mortality or incidence from COVID-19 (y-axis) was plotted against the cumulative percentage of regions ranked by their human development index (HDI) (x-axis) beginning with the lowest HDI on the left, and ending with the highest $\mathrm{HDI}$ on the right. This is one of the best measures of inequalities in different regions with a natural ordering.

\section{Results}

[Figure 1] presents the association of mortality per 100,000 population with cases per 100,000 population. It was found that Log mortality per 100,000 population was positively associated with Log incidence rate per 100,000 population with a correlation coefficient $r=+0.82$ ( $p$-value $=0.0001$ ). Therefore, it is statistically highly significant that the states having high incidence rate of covid19 had also have high mortality rate due to covid19.Delhi had the highest mortality rate and Bihar had the lowest mortality rate in the country in relation to incidence rate.

The regression model is $Y=1.056 \mathrm{X}-4.8755$ where $\mathrm{Y}=$ Log Mortality Rate/0.1M and $\mathrm{X}=$ Log Cases $/ 0.1 \mathrm{M}$ (R-Square=0.6703, p-value $=0.0001$ ).

[Figure 2] presents the association of Case-fatality per 10,000 population with cases per 100,000 population. It was found that Log case-fatality per 10,000 population was not associated with Log incidence rate per 100,000 population with a correlation coefficient $r=-0.078$ ( $p$-value $=0.657$ ).

The regression model is $Y=0.056 X+4.33$ where $Y=$ Log case-fatality rate per 10,000 cases and $X=\log$ Cases/0.1M (Adjusted R-Square $=0.0061$, $p$ value $=0.657)$. The graph is also indicating that many regions of the country deviated from the regression line as shown in the figure.

We analysed the association of various factors such as literacy level, school education up to secondary level per 1000 population, percent of population below poverty line, per capita income in both rupees, and life expectancy at birth, with Incidence rate per 100,000 population. Besides these variables, the level of urbanization i.e. percent of urban population in each regions was also used to determine the association with incidence rate of covid19. 
Results from linear regression models that examined the association between $\mathrm{HDI}$ and its components and the incidence and mortality rates from COVID-19 are presented in [Table 1].

[Figure 3A] presents the association of log of incidence rate per 100,000 population with literacy level of the population. It was found that Log incidence rate per 100,000 population was positively associated with literacy rate (\%) with a correlation coefficient $r=+0.3769$ ( $p$-value $=0.0256$ ). Therefore, it was statistically highly significant that the states having high literacy rate had also high incidence rate of covid19. The regression model is $Y=0.034 X+$ 3.928 where $Y=$ Log Incidence rate/ $0.1 \mathrm{M}$ and $X=$ Literacy rate (\%) (R-Square $=0.1421$, $p$-value $=0.0256$ ). [Figure 3B] presents the association of log of incidence rate per 100,000 population with level of secondary education above 15 years of age per 1000 population. It was found that Log incidence rate per 100,000 population was positively associated with level of secondary education above 15 years of age per 1000 population with a correlation coefficient $r=$ +0.4851 ( $p$-value $=0.0031$ ). Therefore, it was statistically highly significant that the states having high level of secondary education above 15 years of age per 1000 population had also high incidence rate of covid19. The regression model is $Y=0.0069 \mathrm{X}+$ 5.80 where $Y=\log$ Incidence rate $/ 0.1 \mathrm{M}$ and $X=$ level of secondary education above 15 years of age per 1000 population (R-Square $=0.2354, \quad p$ value $=0.0031$ ).

[Figure 3C] presents the association of log of incidence rate per 100,000 population with percent of population below poverty line. It was found that Log incidence rate per 100,000 population was negatively associated with percent of population below poverty line with a correlation coefficient $r=$ 0.42 ( $p$-value $=0.012$ ). Therefore, it was statistically highly significant that the states having low percent of population below poverty line had high incidence rate of covid19. The regression model is $Y=-0.0274 X$ +7.072 where $Y=$ Log Incidence rate $/ 0.1 \mathrm{M}$ and $X=$ percent of population below poverty line ( $R$ Square $=0.1753, p$-value $=0.012$ ).

[Figure 3D] presents the association of log of incidence rate per 100,000 population with log of per capita income (in Rupees). It was found that Log incidence rate per 100,000 population was positively associated with log of per capita income with a correlation coefficient $r=0.654$ ( $p$-value $=0.0001$ ) Therefore, it was statistically highly significant that the states having high per capita income had high incidence rate of covid19. The regression model is $Y$ $=0.9433 \mathrm{X}-4.64$ where $\mathrm{Y}=\log$ Incidence rate $/ 0.1 \mathrm{M}$ and $X=$ Log of Per Capita Income (in Rs.) (RSquare $=0.4276, p$-value $=0.0001$ ).

[Figure 3E] presents the association of log of incidence rate per 100,000 population with life expectancy at birth. It was found that Log incidence rate per 100,000 population was positively associated with life expectancy at birth with a correlation coefficient $r=0.553$ ( $p$-value $=0.0092$ ). Therefore, it was statistically highly significant that the states having high life expectancy at birth had high incidence rate of covid19. The regression model is $Y=0.1289 \mathrm{X}-2.476$ where $Y=\log$ Incidence rate/0.1M and $X=$ Life expectancy at birth ( $R$ Square $=0.3063, p$-value $=0.0092$ ).

Finally, regression analysis was performed to estimate the overall effect of HDI on incidence of Covid19. Figure-3F presents the association of log of incidence rate per 100,000 population with human development index (HDI). It was found that Log incidence rate per 100,000 population was positively associated with $\mathrm{HDI}$ with a correlation coefficient $r=$ 0.658 ( $p$-value $=0.0001$ ). Therefore, it was statistically highly significant that the states having high HDI had high incidence rate of covid19. The regression model is $Y=9.4182 X+0.167$ where $Y=$ Log Incidence rate $/ 0.1 \mathrm{M}$ and $\mathrm{X}=\mathrm{HDI}$ ( $\mathrm{R}$ Square $=0.4333$, $p$-value $=0.0001$ ) .

[Figure 4] presents the association of log of incidence rate per 100,000 population with percent of urban population which indicates level of urbanization in each regions of India. It was found that Log incidence rate per 100,000 population was positively associated with percent of urban population with a correlation coefficient $r=0.573$ ( $p$-value $=0.0003$ ). Therefore, it was statistically highly significant that the states having high level of urbanization had high incidence rate of covid19.The regression model is $Y=$ $0.0216 \mathrm{X}+5.784$ where $Y=\log$ Incidence rate $/ 0.1 \mathrm{M}$ and $X=$ Percent of urban population ( $R$ Square $=0.3286$, $p$-value $=0.0003$ ).

Association of Log Mortality rate/ 100,000 population with HDI and its components

Results from linear regression models that examined the association between HDI and its components and mortality rates from COVID-19 are presented in [Table 1].

[Figure 5A] presents the association of log of mortality rate per 100,000 population with literacy 
level of the population. It was found that Log mortality rate per 100,000 population was positively associated with literacy rate (\%) with a correlation coefficient $r=+0.43$ ( $p$-value $=0.010)$. Therefore, it was statistically highly significant that the states having high literacy rate had also high mortality rate of covid19. The regression model is $Y=0.0497 X-$ 1.797 where $Y=$ Log mortality rate/ $0.1 \mathrm{M}$ and $X=$ Literacy rate $(\%)(R-S q u a r e=0.1853, p$-value $=0.0098)$. [Figure 5B] presents the association of log of mortality rate per 100,000 population with secondary education among 15 years and above per 1000 population. It was found that Log mortality rate per 100,000 population was positively associated with secondary education above 15 years with a correlation coefficient $r=+0.50$ ( $p$-value $=0.0022$ ). Therefore, it was statistically highly significant that the states having high proportion of secondary education above 15-years had also high mortality rate of covid19. The regression model is $Y=0.0091 \mathrm{X}$ +1.054 where $Y=\log$ mortality rate/ $0.1 \mathrm{M}$ and $X=$ Secondary education above 15-years per 1000 population ( $R$-Square $=0.2501, p$-value $=0.0022$ ).

[Figure 5C] presents the association of log of mortality rate per 100,000 population with population below poverty level (\%). It was found that Log mortality rate per 100,000 population was negatively associated with secondary education above 15 years with a correlation coefficient $r=-0.52$ $(p$-value $=0.0014)$. Therefore, it was statistically highly significant that the states having low level of BPL population had high mortality rate of covid19. The regression model is $Y=-0.0435 X+2.86$ where $Y$ $=$ Log mortality rate $/ 0.1 \mathrm{M}$ and $\mathrm{X}=$ Population below poverty line ( $R$-Square $=0.2682$, $p$-value $=0.001$ ).

[Figure 5D] presents the association of log of mortality rate per 100,000 population with log per capita income (in Rupees). It was found that Log mortality rate per 100,000 population was positively associated with per capita income (in Rupees) with a correlation coefficient $r=0.711$ ( $p$-value $=0.0001$ ). Therefore, it was statistically highly significant that the states having high per capita income had high mortality rate of covid19. The regression model is $Y$ $=1.314 \mathrm{X}+2.86$ where $\mathrm{Y}=\mathrm{Log}$ mortality rate $/ 0.1 \mathrm{M}$ and $X=$ log per capita income (Rs.) (RSquare $=0.5060, p$-value $=0.0001$ ) .

[Figure 5E] presents the association of log of mortality rate per 100,000 population with life expectancy at birth (in years). It was found that Log mortality rate per 100,000 population was positively associated with life expectancy at birth with a correlation coefficient $r=0.589$ ( $p$-value $=0.0049$ ). Therefore, it was statistically highly significant that the states having high life expectancy at birth had high mortality rate of covid19. The regression model is $Y=0.172 X-9.91$ where $Y=$ Log mortality rate/0.1M and $X=$ life expectancy at birth ( $R$ Square $=0.3472$, $p$-value $=0.0049$ ).

[Figure 5F] presents the association of log of mortality rate per 100,000 population with human development index (HDI). It was found that Log mortality rate per 100,000 population was positively associated with HDI with a correlation coefficient $r=$ 0.678 ( $p$-value $=0.0001$ ). Therefore, it was statistically highly significant that the states having high HDI had high mortality rate of covid19. The regression model is $Y=12.42 \mathrm{X}-6.38$ where $\mathrm{Y}=\mathrm{Log}$ mortality rate/ $0.1 \mathrm{M}$ and $\mathrm{X}=\mathrm{HDI}$ ( $\mathrm{R}$-Square $=0.4596$, $p$-value $=0.0001$ ).

[Figure 6] presents the dependence of log of mortality rate per 100,000 population on percent of urban population which indicates level of urbanization in each regions of India. It was found that Log mortality rate per 100,000 population was positively associated with percent of urban population with a correlation coefficient $r=0.621$ ( $p$ value $=0.0001$ ). Therefore, it was statistically highly significant that the states having high level of urbanization had high incidence rate of covid19. The regression model is $Y=0.03 X+0.9769$ where $Y=\log$ mortality rate $/ 0.1 \mathrm{M}$ and $\mathrm{X}=$ Percent of urban population ( $R$-Square $=0.3863, p$-value $=0.0001$ ).

[Figure 7] shows concentration curves for the outcome measures analysed in this study. The horizontal axis represents the cumulative percentage of the population ranked by HDI with the origin as the lowest human development index. The cumulative percentage of incidence and mortality rate from COVID-19 corresponding to the cumulative percentage of $\mathrm{HDI}$ is recorded on the vertical axis. Concentration index and $95 \% \mathrm{Cl}$ were 0.41 (0.27$0.54)$ for incidence rate of COVID-19 and 0.42 (0.26$0.58)$ for COVID-19 mortality rate.

\section{Discussion}

In this ecological study, we have used the data of total COVID19 cases and Deaths per 100,000 population for examining the statistical relationship with variables such as literacy rate(\%), secondary education 15 -years and above per 1000 population, proportion of population below poverty line, per 

capita income (in Rs.), life expectancy at births in years and Human development index (HDI). Besides these variables, urban density, which is measured as percent of urban population in regions was also used to see the effect of urbanization on morbidity and mortality of COVID-19. Statistically significant relationships were found with all indicators with that of Cases and Deaths per 100,000 population.

We have found a very strong statistically significant association of Deaths with Cases per 100,000 population with a correlation coefficient of $r=0.82$ ( $p$-value $=0.0001$ ). This statistically significant association clearly indicates that the more are cases per 100,000 population in states or union territories the more are deaths per 100,000 population. A similar association at the country level was observed in a study conducted at the global level.(18) Timely and effective implementations of the necessary pandemic restrictions in the states was a correct decision by the health policy makers of the country. Human Development Index (HDI) was considered as an indicator of the socio-economic status of the states and union territories, and its effect on the incidence and mortality rates of COVID-19 was examined. In this study, it was observed that HDI was significantly associated with incidence and mortality rates, hence, indicating that with increasing HDI both incidence and mortality rates also increasing. The high incidence rate in states and union territories (UTs) with high HDI could be attributed to the effective health-care system for early detection of disease and effective implementation of screening programmes to diagnose the cases. The states with high HDI like Kerala, Delhi, Punjab, Tamil Nadu, Haryana, Maharashtra etc. and UTs like Chandigarh, Puducherry, Andaman and Nicobar Islands had reported high incidence of COVID-19. However, the states with low HDI like Bihar, UP, Odisha, Chattisgarh, MP had reported low number of cases because of not proper infra-structure of health-care systems for early detection and lack of proper implementation of screening programme. This could be due to low quality of registration and reporting system, which could lead to under reporting of disease in some state and UTs.

The three important components of HDI i.e. life expectancy at birth, education level and income level had also showed a significant positive association with incidence and mortality rates of COVID-19. High life expectancy of the population is an indicator of increasing the elderly population. The results of various studies had shown higher incidence and mortality in COVID-19 in the elderly population as compared to other age stratums of the population. The result of this study had also reflected the similar observation, which is very consistent with the results of other studies. The older people are at high risk of progressing to severe cases of the disease and their immune system is less able to cope up with the severity and infectious challenges.(19) $(20,21)$

Education status of state and UTs was measured using two important variables: Literacy Level (\%) and Secondary education above 15-years of age per 1000 population. Both these variables had shown a very high significant association with incidence and mortality rates of COVID-19. High educational level could be an indicator of increased level of health literacy and awareness of early symptoms of disease leading to early detection which would directly increase the incidence reporting.

Income level was measured using two important variables: Percent of population below poverty line (BPL) and Per Capita Income (In Rupees or US\$). There was a significant negative association of BPL with incidence and mortality rates of COVID-19 in India. The states having high percent of population living below poverty line had low incidence and mortality rates whereas the states having low BPL had high incidence and mortality rates. The states having high per capita income (in Rupees or US\$) had shown a high positive association with incidence and mortality rates. Most of the state having high per capita income are comparatively more developed in terms of modern infra-structure and industrialization which could directly affect the freedom of movement and assembly on public facilities leading to minimization of social distancing. This could adversely increase the transmission probability among the population leading to high incidence rate. High proportion of urban population is also a factor of development and industrialization.

The positive value of the concentration index and the placement of the concentration curve below the equality line indicate that morbidity and mortality of COVID-19 are more concentrated in regions with high socio-economic status. Thus, the concentration index showed a higher socio-economic disparity on incidence and mortality rates of COVID-19.

\section{Conclusion}

As per the results of this study, the high incidence and mortality rates of COVID-19 in regions with high 
INDIAN JOURNAL OF COMMUNITY HEALTH / VOL 32 / ISSUE NO 04 / OCT - DEC 2020 $\mathrm{HDI}$ and other components are remarkable, and the national health policy makers should give high priority in implementation of programmes to reduce the burden of this disease in those states with high incidence and mortality rates of COVID-19.

\section{Recommendation}

The results of the study show that the morbidity and mortality of COVID-19 are more concentrated in regions with high socio-economic status and education which reflects more health awareness of early symptoms leading to early detection which would directly increase the incidence reporting.

\section{Limitation of the study}

There were some limitations of this study. Since this was an ecological study, hence the inherent limitation of this study design could be ecological fallacy, which is described as the bias that may occur because of relationship observed among variables on an aggregate level cannot be applicable to the relationship that exists at an individual level. Second, the statistical methods for controlling the influences of confounding variables cannot be applied in the ecological study. Hence, the estimate of effects are largely biased, and do not provide a powerful examination of a causal hypothesis but can be used for generating the hypothesis. Third, regions specific HDI data and its components are of not of the same time period which could compromise the actual estimates.

\section{Relevance of the study}

A general perception which is there in the mass is that the less education and low socioeconomic status has high incidence of disease (especially communicable diseases). But the findings of the current study shows the opposite, that is higher the socioeconomic status and literacy, higher the incidence of the Coronavirus disease.

\section{Authors Contribution}

All authors have contributed equally in the preparation of the manuscript.

\section{References}

1. Lu R, Zhao X, Li J, Niu P, Yang B, Wu H, et al. Genomic characterisation and epidemiology of 2019 novel coronavirus: implications for virus origins and receptor binding. The Lancet. 2020;395(10224):565-74.

2. Riou J, Althaus CL. Pattern of early human-to-human transmission of Wuhan 2019 novel coronavirus (2019nCoV), December 2019 to January 2020. Euro Surveill. 2020;25(4):2000058.

doi:

$10.2807 / 1560-$
[Socio-economic inequality...] | Ranjan A et al 7917.ES.2020.25.4.2000058. Erratum in: Euro Surveill. 2020;25(7): PMID: 32019669; PMCID: PMC7001239.[PubMed].

3. Coronavirus Update (Live): 108,293,836 Cases and 2,378,759 Deaths from COVID-19 Virus Pandemic Worldometer [Internet]. [cited 2020 Dec 22]. Available from: https://www.worldometers.info/coronavirus/

4. Coronavirus in India: Latest Map and Case Count [Internet]. Available from: https://www.covid19india.org [cited 2020 Dec 20]

5. Zhou $P$, Yang XL, Wang XG, Hu B, Zhang L, Zhang W, Si HR, Zhu Y, Li B, Huang CL, Chen HD, Chen J, Luo Y, Guo H, Jiang $R D$, Liu $M Q$, Chen $Y$, Shen $X R$, Wang $X$,Zheng $X S$, Zhao K, Chen QJ, Deng F, Liu LL, Yan B, Zhan FX, Wang YY, Xiao GF, Shi ZL. A pneumonia outbreak associated with a new cor navirus of probable bat origin. Nature. 2020;579(7798):270-273. doi: 10.1038/s41586-0202012-7. Epub 2020 Feb 3. PMID: 32015507; PMCID: PMC7095418.[PubMed].

6. showPdf.pdf [Internet]. Available from: https://www.thelancet.com/action/showPdf?pii=S0140 -6736\%2820\%2930211-7 [cited 2020 Dec 20]

7. Kolifarhood G, Aghaali M, Mozafar Saadati H, Taherpour $\mathrm{N}$, Rahimi S, Izadi N, Hashemi Nazari SS. Epidemiological and Clinical Aspects of COVID-19; a NarrativeReview. Arch Acad Emerg Med. 2020 1;8(1):e41. PMID: 32259130; PMCID: PMC7117787.[PubMed].

8. Sub-national HDI - Subnational HDI - Global Data Lab [Internet]. Available from: https://globaldatalab.org/shdi/

shdi/IND/?levels=1\%2B4\&interpolation=0\&extrapolatio $\underline{\mathrm{n}=0 \text { \&nearest real }=0}$ [cited 2020 Dec 20]

9. Khazaei Z, Goodarzi E, Borhaninejad V, Iranmanesh F, Mirshekarpour H, Mirzaei B, Naemi H, Bechashk SM, Darvishi I, Ershad Sarabi R, Naghibzadeh-Tahami A. The association between incidence and mortality of brain cancer and human development index (HDI): an ecological study. BMC Public Health. 2020 12;20(1):1696. doi: 10.1186/s12889-020-09838-4. PMID: 33183267; PMCID: PMC7664078.[PubMed].

10. Goodarzi E, Sohrabivafa M, Darvishi I, Naemi H, Khazaei Z. Epidemiology of mortality induced by acute respiratory infections in infants and children under the age of 5 years and its relationship with the Human Development Index in Asia: an updated ecological study. J Public Health. 2020;10;

11. state-wise-aadhaar-saturation.pdf [Internet]. [cited 2020 Dec 22]. Available from: https://uidai.gov.in/images/state-wise-aadhaarsaturation.pdf

12. Census of India: Sample Registration System (SRS) Bulletins [Internet]. Available from: https://censusindia.gov.in/vital statistics/SRS Bulletins/Bulletins.aspx [cited 2020 Dec 20]

13. Report_585_75th_round_Education_final_1507_0.pdf [Internet]. Available from: http://mospi.nic.in/sites/ default/files/publication_reports/Report_585 75th_ro und Education final 1507 0.pdf [cited 2020 Dec 20] 
INDIAN JOURNAL OF COMMUNITY HEALTH / VOL 32 / ISSUE NO 04 / OCT - DEC 2020

14. Reserve Bank of India - Publications [Internet]. Available from: https://www.rbi.org.in/scripts/publicationsview. aspx?id=12043 [cited 2020 Dec 20]

15. Second Advance Estimates of National Income, 2019-20 and Quarterly Estimates of Gross Domestic Product for the Third Quarter (Oct-Dec), 2019-20 [Internet]. Available from: https://pib.gov.in/Pressreleaseshare.aspx?PRID=16046 77 [cited 2020 Dec 20]

16. paper2_1.pdf [Internet]. Available from: https://censu sindia.gov.in/2011-provresults/paper2/data files/india/ paper2 1.pdf [cited 2020 Dec 20]

17. Valev D. Relationships of total COVID-19 cases and deaths with ten demographic, economic and social indicators [Internet]. Epidemiology; 2020 Sep Available from:

http://medrxiv.org/lookup/doi/10.1101/2020.09.05.20 188953 [cited 2020 Dec 20]

18. Choi KW, Chau TN, Tsang O, Tso E, Chiu MC, Tong WL, Lee PO, Ng TK, Ng WF, Lee KC, Lam W, Yu WC, Lai JY, Lai ST; Princess Margaret Hospital SARS Study Group.
[Socio-economic inequality...] | Ranjan A et al Outcomes and prognostic factors in 267 patients with severe acute respiratory syndrome in Hong Kong. Ann Intern Med. 2003 4;139(9):715-23. doi: 10.7326/00034819-139-9-200311040-00005.

PMID: 14597455.[PubMed].

19. Hong KH, Choi JP, Hong SH, Lee J, Kwon JS, Kim SM, Park SY, Rhee JY, Kim BN, Choi HJ, Shin EC, Pai H, Park SH, Kim $\mathrm{SH}$. Predictors of mortality in Middle East respiratory syndrome (MERS). Thorax. 2018 Mar;73(3):286-289. doi: 10.1136/thoraxjnl-2016-209313. Epub 2017 19. PMID: 28724637.[PubMed].

20. Zhou F, Yu T, Du R, Fan G, Liu Y, Liu Z, Xiang J, Wang Y, Song B, Gu X, Guan L, Wei Y, Li H, Wu X, Xu J, Tu S, Zhang $Y$, Chen $H$, Cao B. Clinical course and risk factors for mortality of adult inpatients with COVID-19 in Wuhan, China: a retrospective cohort study. Lancet. 2020 28;395(10229):1054-1062. doi:10.1016/S0140 6736(20)30566-3. Epub 2020 Mar 11. Erratum in: Lancet. 2020 Mar 28;395(10229):1038. Erratum in: Lancet. 2020 28;395(10229):1038. PMID: 32171076; PMCID: PMC7270627.[PubMed].

\section{Tables}

TABLE 1 EFFECT OF HUMAN DEVELOPMENT INDEX AND ITS COMPONENTS ON COVID-19 INCIDENCE AND MORTALITY RATES IN INDIA

\begin{tabular}{|c|c|c|c|c|c|c|}
\hline \multirow[t]{2}{*}{ Variables } & \multicolumn{3}{|c|}{ Log( Incidence rate/100000) of Covid19 } & \multicolumn{3}{|c|}{ Log( Mortality rate/100000) of Covid19 } \\
\hline & $\begin{array}{l}\text { Beta } \\
\text { coefficient }\end{array}$ & $\begin{array}{l}95 \% \text { Confidence } \\
\text { Interval }\end{array}$ & $\begin{array}{l}\mathrm{P} \\
\text { values }\end{array}$ & $\begin{array}{l}\text { Beta } \\
\text { coefficient }\end{array}$ & $\begin{array}{l}95 \% \text { Confidence } \\
\text { Interval }\end{array}$ & $\begin{array}{l}\mathrm{P} \\
\text { values }\end{array}$ \\
\hline \multicolumn{7}{|l|}{ A. Education Level } \\
\hline I. Literacy Level(\%) & 0.0340 & $0.0044-0.0636$ & 0.0256 & 0.0495 & $0.0128-0.0867$ & 0.010 \\
\hline $\begin{array}{l}\text { II. School Education up to secondary } \\
\text { Level (Per } 1000 \text { population) }\end{array}$ & 0.0069 & $0.0025-0.0113$ & 0.0031 & 0.0091 & $0.0035-0.0147$ & 0.002 \\
\hline \multicolumn{7}{|l|}{ B. Income Level } \\
\hline $\begin{array}{l}\text { I. Percent of Population Below } \\
\text { poverty Line }\end{array}$ & -0.0274 & $\begin{array}{l}-0.0484-(-) \\
0.0063\end{array}$ & 0.012 & -0.043 & $\begin{array}{l}-0.069-(-) \\
0.0180\end{array}$ & 0.001 \\
\hline II. Log Per Capita Income (In Rs.) & 0.9433 & $0.556-1.329$ & 0.0001 & 1.315 & $0.854-1.77$ & 0.0001 \\
\hline III. Log Per Capita Income(In US\$) & 0.9645 & $0.578-1.35$ & 0.0001 & 1.342 & $0.884-1.80$ & 0.0001 \\
\hline \multicolumn{7}{|l|}{ C. Health } \\
\hline I. Life Expectancy at Birth & 0.128 & $0.036-0.222$ & 0.0092 & 0.172 & $0.0589-0.285$ & 0.005 \\
\hline Health Development Index (HDI) & 9.42 & $5.60-13.23$ & 0.0001 & 12.428 & $7.65-17.20$ & 0.0001 \\
\hline \multicolumn{7}{|l|}{ D. Other Factors } \\
\hline I. Urban Population (\%) & 0.0216 & $0.0106-0.0325$ & 0.0003 & 0.030 & $0.0162-0.0434$ & 0.0001 \\
\hline
\end{tabular}




\section{Figures}

FIGURE 1 ASSOCIATION OF MORTALITY DUE TO COVID19 PER 100,000 POPULATION WITH CASES PER 100,000 POPULATION.

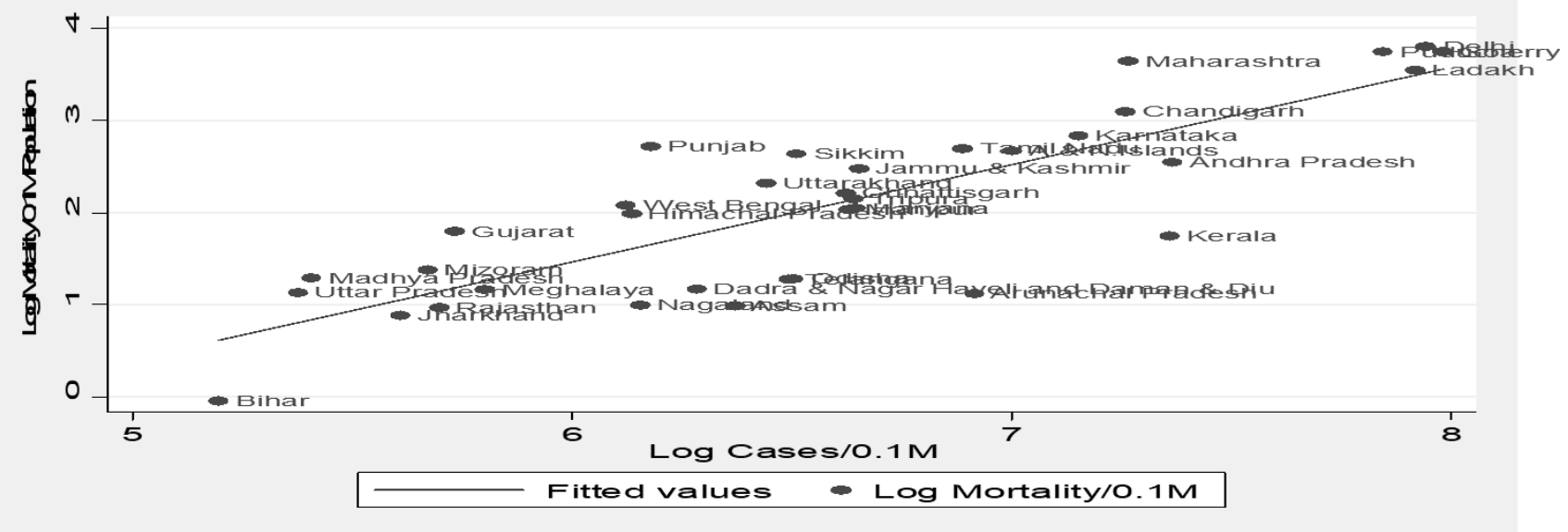

FIGURE 2 ASSOCIATION OF CASE-FATALITY PER 10,000 POPULATION FROM CASES PER 100,000 POPULATION

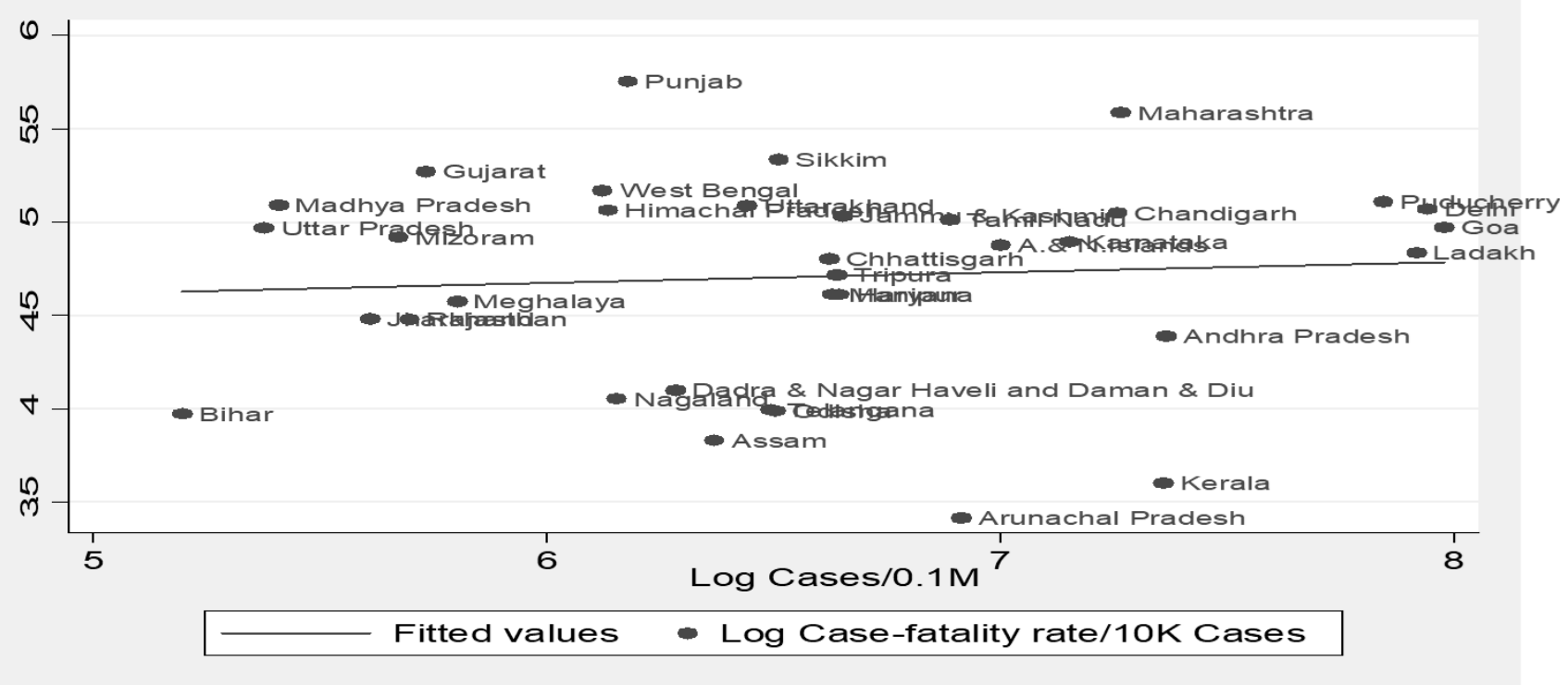

FIGURE 3 ASSOCIATION OF LOG INCIDENCE RATE PER 100,000 POPULATION WITH HUMAN DEVELOPMENT INDEX (HDI) AND ITS COMPONENTS
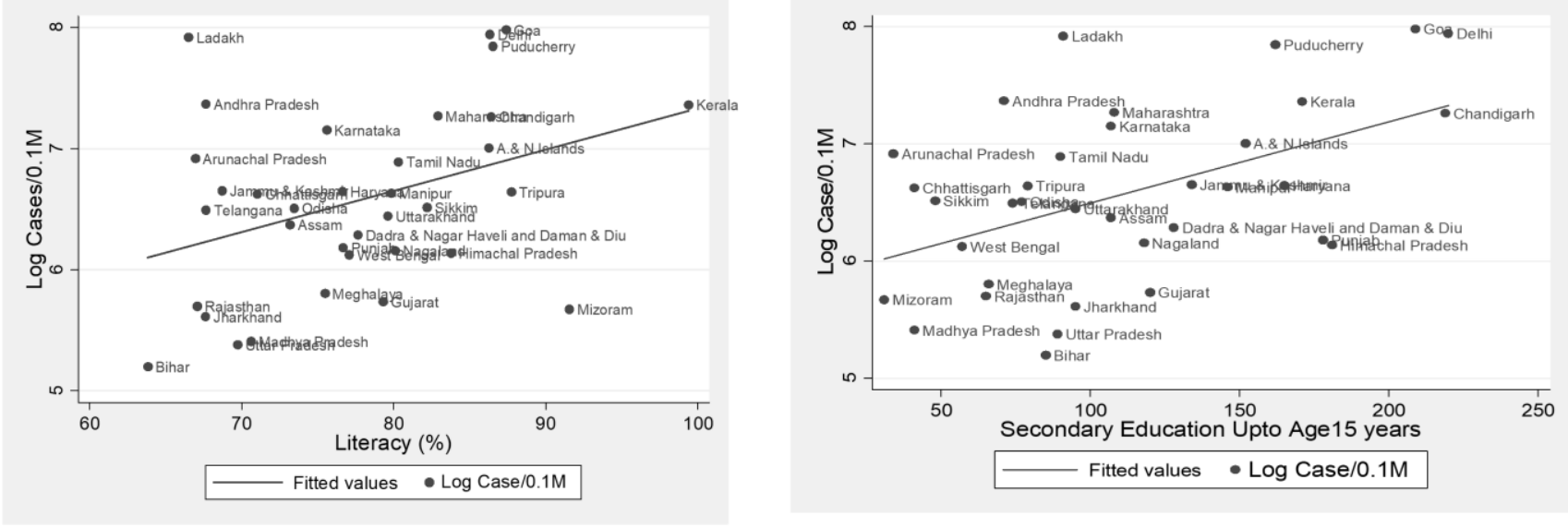

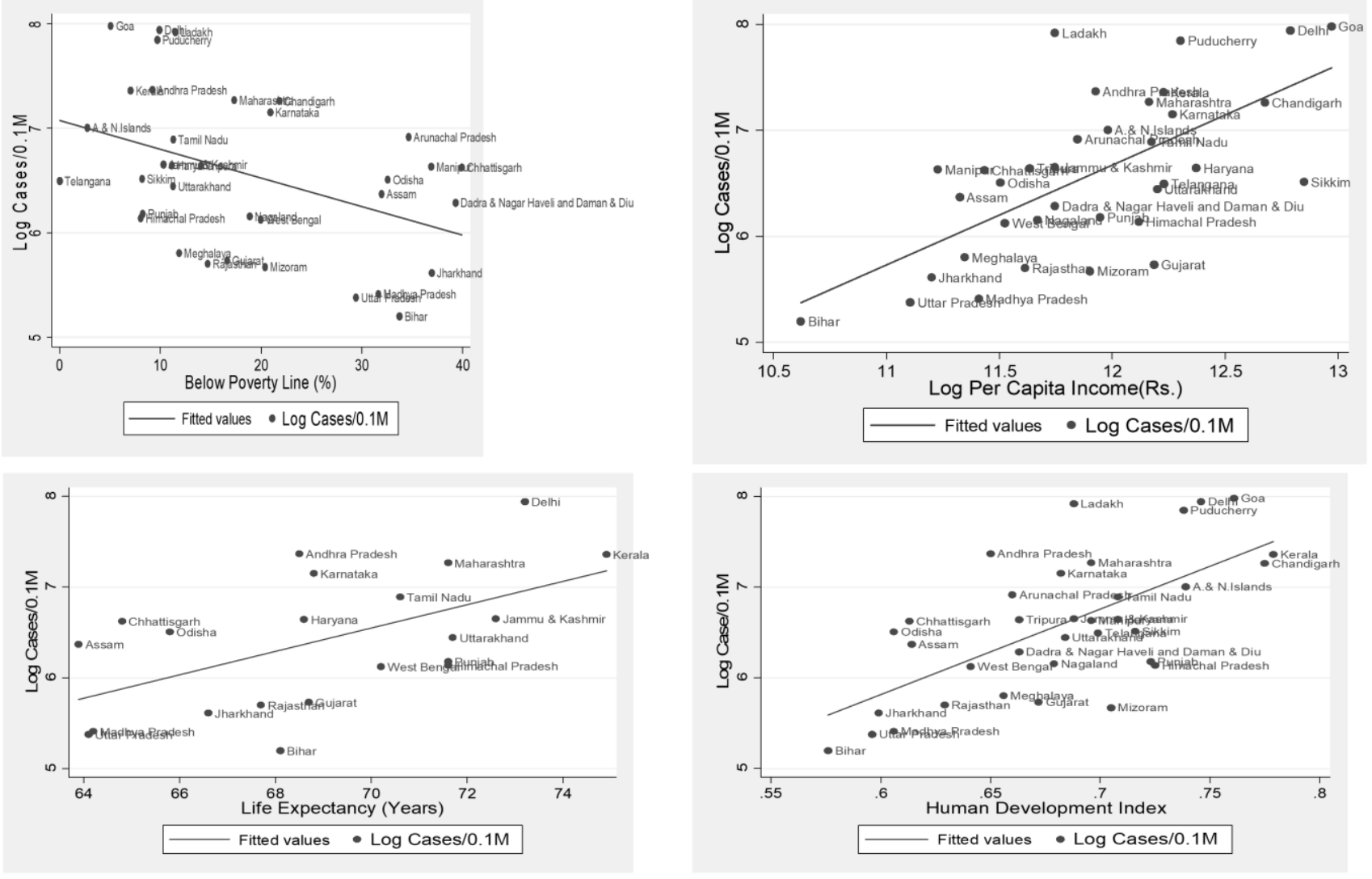

\section{FIGURE 4 ASSOCIATION OF LOG INCIDENCE RATE PER 100,000 POPULATION FROM URBAN POPULATION (\%)}

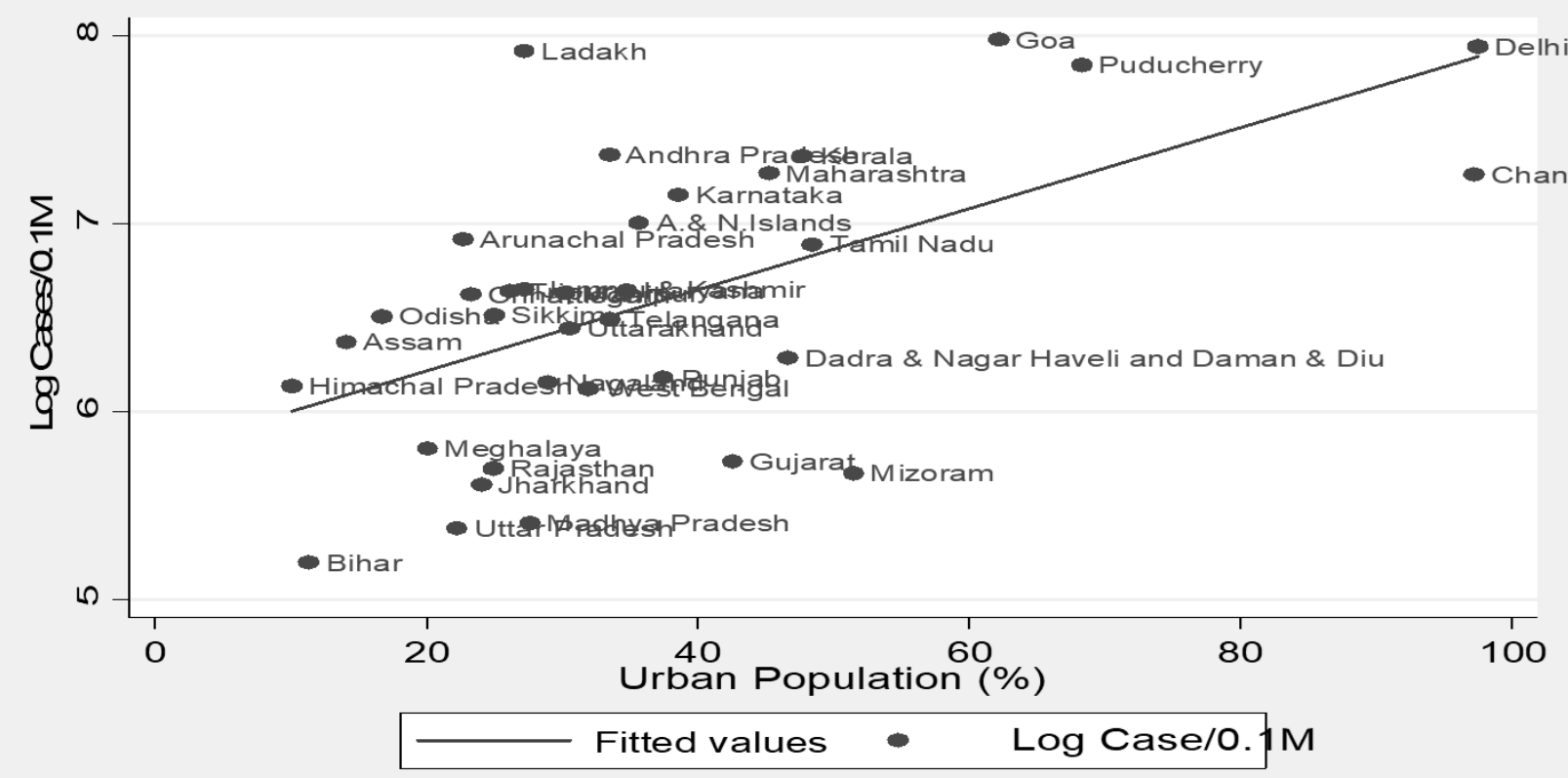




\section{FIGURE 5 ASSOCIATION OF LOG MORTALITY RATE PER 100,000 POPULATION WITH HUMAN DEVELOPMENT INDEX (HDI) AND ITS COMPONENTS}
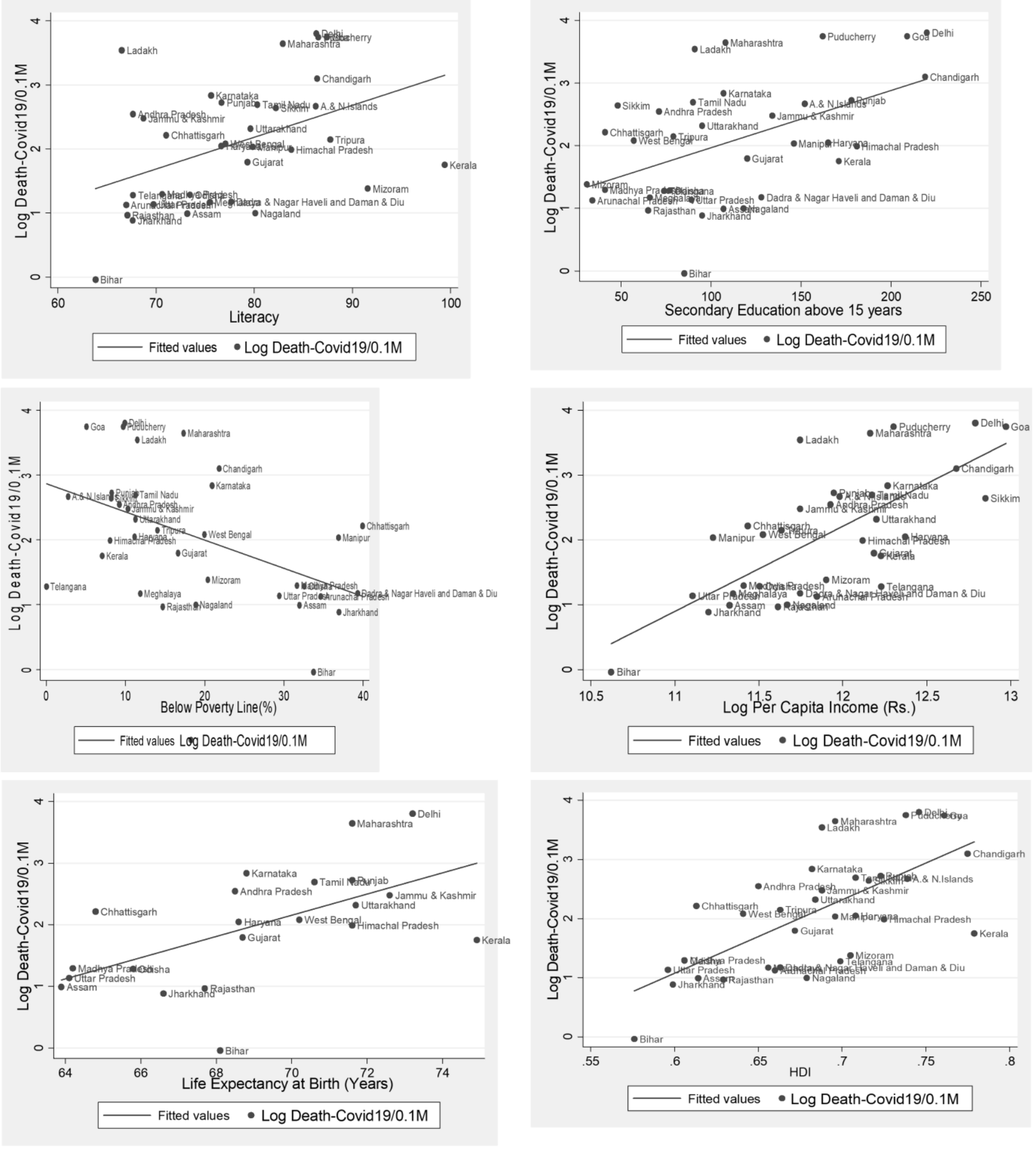
FIGURE 6 ASSOCIATION OF LOG MORTALITY RATE PER 100,000 POPULATION ON URBAN POPULATION (\%)

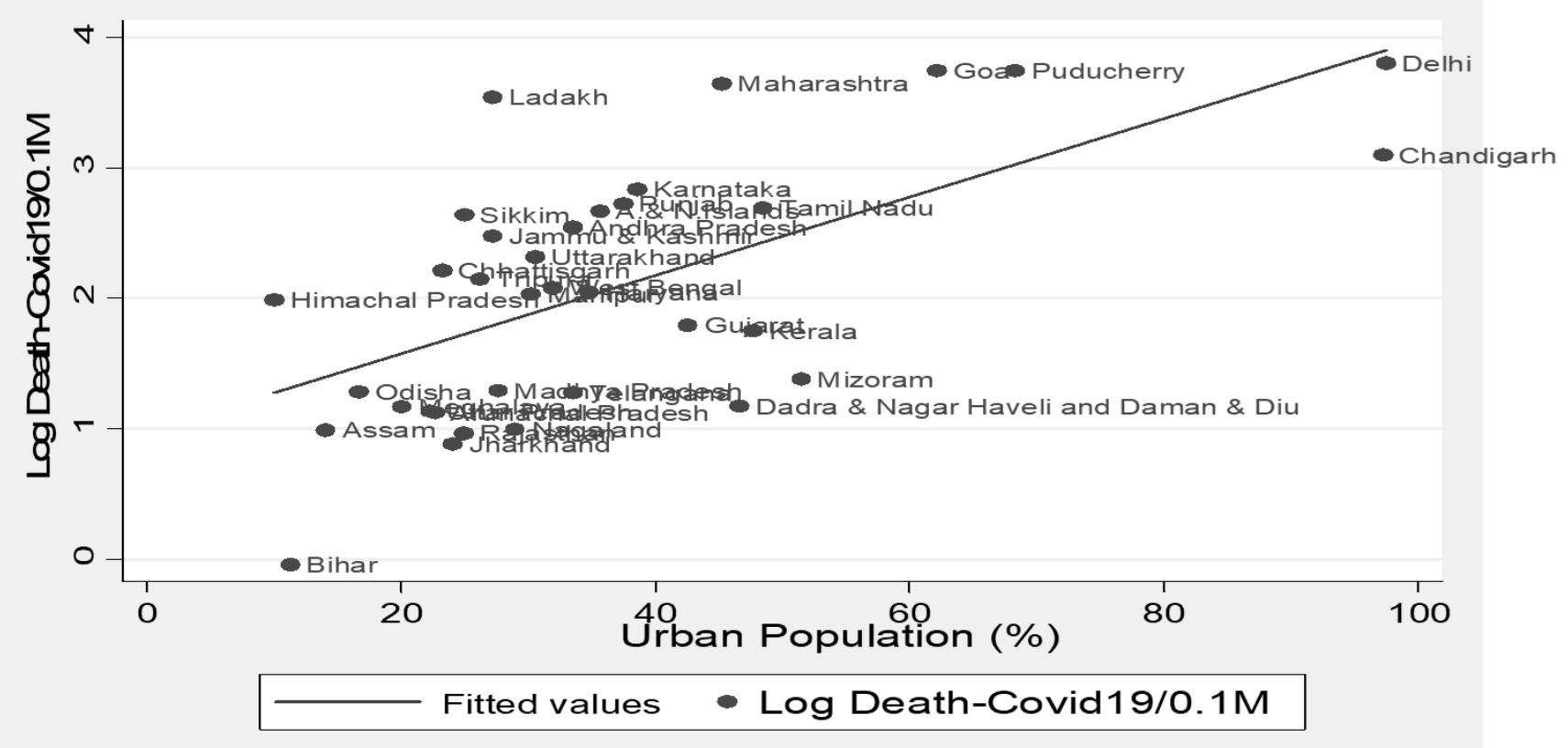

\section{FIGURE 7 CONCENTRATION CURVE FOR MEASURING SOCIO-ECONOMIC INEQUALITY IN INCIDENCE} AND MORTALITY RATE FROM COVID-19 RANKED BY HUMAN DEVELOPMENT INDEX IN INDIA

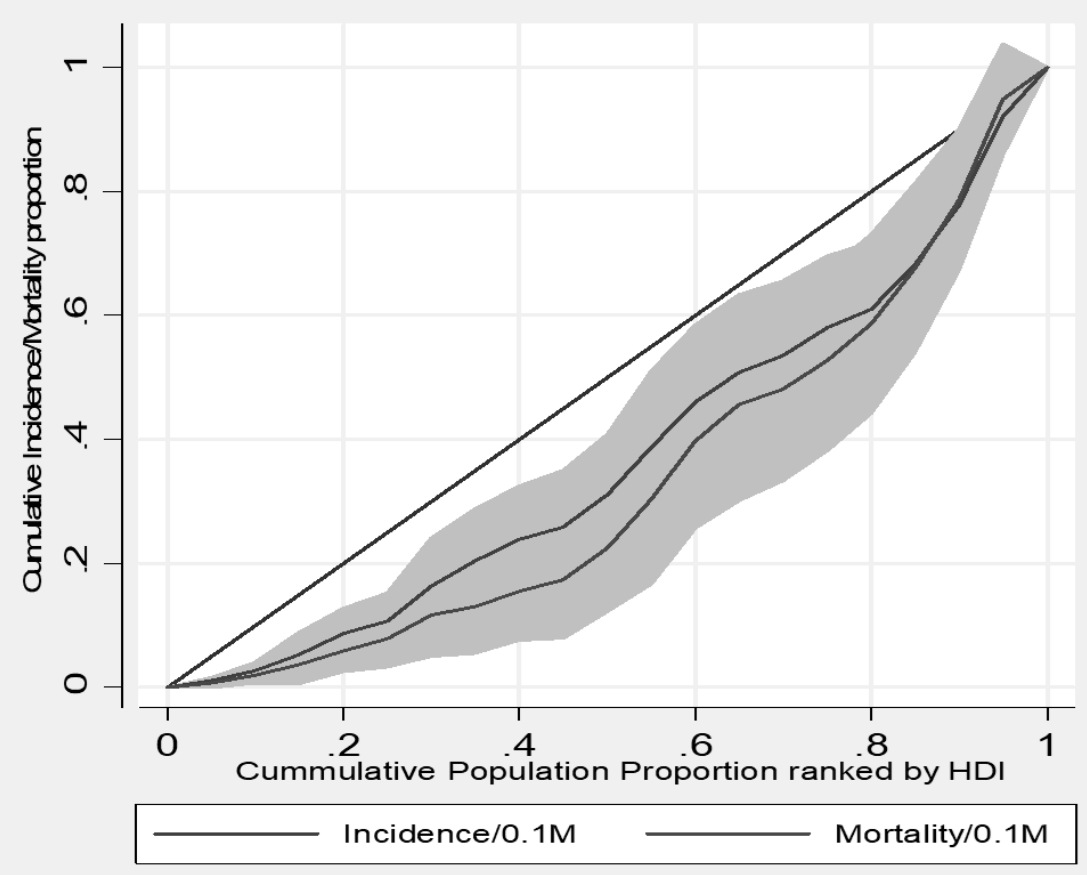

